\title{
Colonic polyp presenting as a tubulovillous adenoma and harbinger of high-grade neuroendocrine carcinoma: a unique presentation
}

\author{
Ogechukwu Eze, Saul Harari, Margaret Cho, Antonio Galvao Neto \\ Department of Pathology, New York University Langone Medical Center, New York, United States
}

Correspondence: Antonio Galvao Neto. Address: Department of Pathology and Laboratory Medicine, NYU Langone Medical Center, 560 First Avenue, HW 476, New York, NY 10016, United States. E-mail: Antonio.GalvaoNeto@nyumc.org

Received: August 14, 2014

Accepted: August 30, 2014

Online Published: October 24, 2014

DOI : $10.5430 /$ crcp.v2n1p67

URL: http://dx.doi.org/10.5430/crcp.v2n1p67

\begin{abstract}
High-grade neuroendocrine carcinomas (HGNEC) of the colon are rare. However, when they occur, there is evidence to support a strong association with tubulovillous/villous adenomas (TVA). We present a unique case of a colonic TVA associated with HGNEC in a 64-year-old woman with a large polypoid mass in the rectosigmoid colon diagnosed as TVA with high-grade dysplasia (HGD) on biopsy. Pathologic examination revealed a $4.8 \mathrm{~cm}$ friable polypoid mass composed of two morphologically distinct elements. The luminal portion of the tumor consisted of a TVA with areas of HGD. A distinct component was identified deeper to the adenoma, consisting of nested small-to-medium sized cells with increased nuclear-to-cytoplasmic ratio, nuclei exhibiting finely dispersed chromatin, inconspicuous nucleoli, patchy areas of necrosis, and increased mitotic figures. The two tumor components were closely apposed with focal areas of intermixing at their interface. Immunohistochemistry demonstrated diffuse positive staining of the deeper, nested neoplastic cells with synaptophysin, chromogranin, CD56 and CAM 5.2 and a perinuclear-dotlike pattern of pancytokeratin AE1/AE3 staining. The proliferation index was up to $90 \%$ (Ki-67). Given the overall findings, a diagnosis of HGNEC arising in a background of TVA was rendered. This unique case is one of the few reported cases of mixed adenoma HGNEC involving the colon. This case demonstrates possible pitfalls in diagnosis. Superficial biopsies often do not provide adequate representation of underlying neuroendocrine neoplasms. In this case, metastatic HGNEC was identified although initial biopsy revealed only TVA, suggesting that the two lesions were unrelated.
\end{abstract}

\section{Key words}

High-grade neuroendocrine carcinoma, Tubulovillous adenoma

\section{I ntroduction}

Neoplasms comprising of both glandular and neuroendocrine components, so-called mixed neoplasms, have been described in the large intestine ${ }^{[1-3]}$. Both tubular adenoma and well-differentiated neuroendocrine tumors (carcinoid) of the tubular gastrointestinal tract are relatively common with well-differentiated neuroendocrine tumors most commonly found in the small intestine (25\%), appendix (12\%) and rectum $(14 \%)^{[4-6]}$. However, mixed endocrine-glandular neoplasms of the large intestine are rare tumors and are defined as glandular neoplasms containing morphologically recognizable endocrine components that occupy substantial proportions of the tumor, either diffusely (combined tumors) 
or locally (composite tumors) ${ }^{[1-3]}$. The "composite adenoma carcinoid" exhibits benign histological features in both the glandular and neuroendocrine components. The distinction between true composite tumors and collisions between adenomas and carcinoids can be difficult and depends mainly on the demonstration of histologic blending of the glandular and endocrine elements. In contrast, high-grade neuroendocrine carcinomas of the tubular gastrointestinal tract have increased mitotic activity or proliferation index (> 20/hpf or 20\% respectively) and are rare with the esophagus as the most common site (50\% of reported cases) ${ }^{[7-11]}$. Staging of localized tumors is dependent upon size (greater or less than $2 \mathrm{~cm}$ ) and depth of invasion ${ }^{[12-14]}$. Here we present the rare finding of a colonic tubulovillous adenoma associated with highgrade neuroendocrine carcinoma.

\section{Case presentation}

A 64-year-old woman presented complaining of intermittent lower abdominal pain exacerbated by defecation with bright red blood per rectum. Her past medical history was significant for multiple colonic polyps. These polyps were detected and removed at an outside institution, and prior records of the procedure were unavailable. According to the patient, the polyps were benign. Subsequently, the patient was under routine colonoscopic surveillance. She also reported experiencing general, constitutional symptoms prompting a more extensive work-up. Imaging studies revealed multiple lesions involving the liver and skeletal system. A biopsy of the bone lesion revealed a high grade neuroendocrine carcinoma. However, the site of origin was unclear. Colonoscopy detected a large polypoid mass in the rectosigmoid colon, which on biopsy revealed tubulovillous adenoma with high grade dysplasia. Ultimately, the patient underwent a low anterior resection with colorectal anastamosis and loop ileostomy formation.

The corresponding pathology specimen consisted of a $26 \mathrm{~cm}$ segment of sigmoid colon and rectum with intact mesorectum. A $4.8 \mathrm{~cm} \times 3.5 \mathrm{~cm} \times 1.3 \mathrm{~cm}$ friable, polypoid mucosal mass was identified in the rectum. Overt invasion into the colonic wall was not seen. Additional multiple polyps were identified, with the largest measuring up to $0.2 \mathrm{~cm}$ in greatest dimension.

Microscopic examination of the largest mass revealed a neoplasm composed of two morphologically distinct elements. The luminal portion of the tumor consisted of a typical tubulovillous adenoma (irregular tubules and villi with enlarged, hyperchromatic, stratified nuclei) with areas of high grade dysplasia. A minor but distinct component was identified deeper to the adenoma, which consisted of nested small-to-medium sized cells with increased nuclear-to-cytoplasmic ratio, nuclei exhibiting finely dispersed chromatin, and inconspicuous nucleoli. Patchy areas of necrosis and increased mitotic figures were noted within this component. It measured $2 \mathrm{~cm}$ in greatest dimension, and submucosal invasion was identified along with lymphatic invasion. The two tumor components were closely apposed with focal areas of intermixing at their interface. All other polyps were hyperplastic. Tumor deposits were identified in the pericolonic fat, and thirteen harvested lymph nodes were uninvolved by carcinoma (see Figure 1).

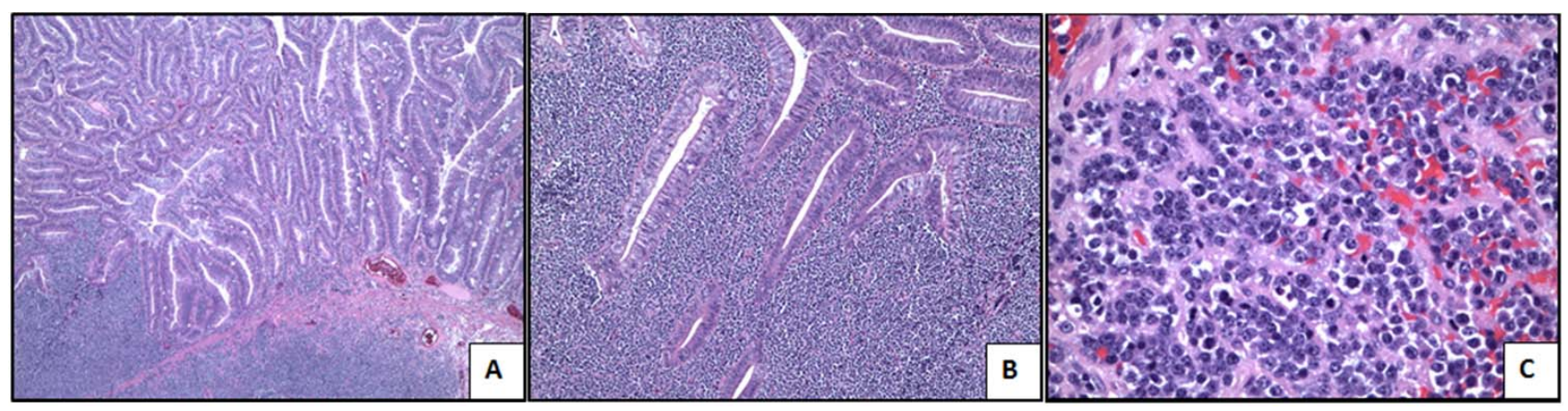

Figure 1. Tubulovillous adenoma with closely apposed (A, H\&E 40×) and focally intermixed (B, H\&E 100×) tumor component composed of small-to-medium sized cells with enlarged nuclei exhibiting finely dispersed chromatin and inconspicuous nucleoli (C, H\&E 400×). 
Immunohistochemical analysis demonstrated diffuse positive staining of the deeper, nested neoplastic cells with synaptophysin, chromogranin, CD56 and CAM 5.2. Pancytokeratin AE1/AE3 produced a perinuclear-dotlike pattern of staining. The proliferation index of these cells, as measured by Ki-67, was up to $90 \%$. Other immunostains, including CD45, CD3, CD20, CD79a, TTF-1, CDX-2 and CK20 were all negative in these nested cells. Given the overall findings, a diagnosis of high-grade neuroendocrine carcinoma arising in a background of tubulovillous adenoma was rendered (see Figure 2).

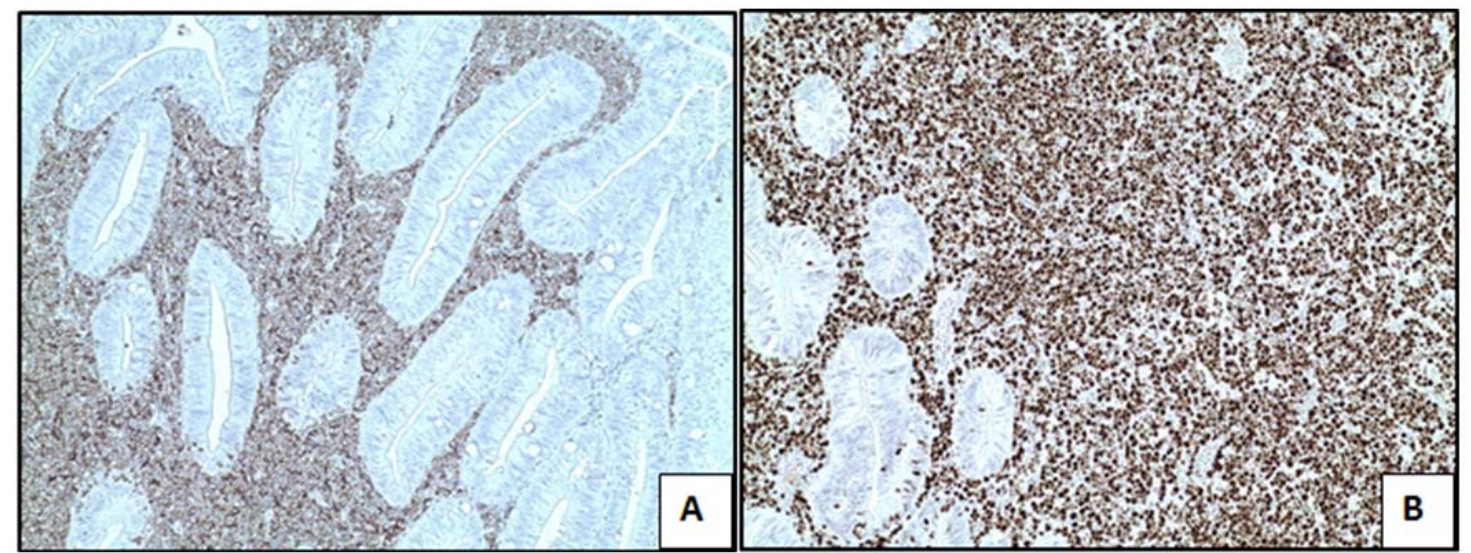

Figure 2. Immunohistochemical analysis demonstrated diffuse positive staining of the deeper, nested neoplastic cells for synaptophysin (A, H\&E 100×), chromogranin, CD56 and CAM 5.2. The proliferation index shown by Ki-67 was up to $90 \%$ (B, H\&E, 100×).

\section{Discussion}

The adenoma-to-carcinoma sequence in colorectal carcinogenesis is a widely accepted model as these lesions are often seen concomitantly with in situ and invasive adenocarcinoma. Removal of these lesions prevents the development of subsequent adenocarcinoma. The relationship of these precursor glandular lesions to neuroendocrine neoplasms of the gastrointestinal tract is, however, less well-understood.

Not uncommonly, isolated neuroendocrine lesions in the form of low-grade (defined by low mitotic activity and proliferation index), or well-differentiated (organoid growth pattern of non-functional cells and strong and diffuse immunohistochemical staining for synaptophysin and chromogranin) neuroendocrine tumors arise within the gastrointestinal tract, most often affecting the small intestine (25\%), rectum (14\%) and appendix (12\%) ${ }^{[4-6]}$. These lesions have traditionally been referred to as carcinoid tumors. Rarely, high-grade neuroendocrine carcinomas, which have increased mitotic activity or proliferation index (> 20/hpf or $20 \%$ respectively), arise in the gastrointestinal tract, with the esophagus representing the most common site of involvement $(50 \%){ }^{[7-11]}$. Staging of localized tumors is dependent upon size (greater or less than $2 \mathrm{~cm}$ ) and depth of invasion ${ }^{[12-14]}$.

Neoplasms comprised of both glandular and neuroendocrine components, so-called mixed neoplasms have also been described ${ }^{[1-3]}$. In the classification by Lewin in 1987, the term "mixed tumor" became widely adopted and was restricted to those neoplasms in which neuroendocrine cells consisted of at least $30 \%$ of the tumor ${ }^{[2]}$. These lesions have further been divided into combined tumors, where the two elements are diffusely intermixed and composite tumors, which are characterized by general demarcation between the two elements with only focal areas of blending. For example, a composite adenoma carcinoid would consist of one tumor with two relatively benign/low-grade components that are mostly segregated from one another. Given the above definitions, it is not surprising that the distinction of a true mixed lesion from a collision lesion of two etiologically distinct neoplasms is often difficult. 
Some have argued, based on the association of neuroendocrine carcinomas/neoplasms to adenomas, adenocarcinomas and even squamous cell carcinoma, that both components of a mixed neoplasm are derived from a single transformed pluripotent stem cell, which could otherwise potentially differentiate into mucus, ciliated or endocrine cells ${ }^{\text {[9-11, 15-17] }}$. Recent molecular studies, however, have failed to show shared molecular/genetic pathways including loss of heterozygosity or imbalance of polymorphic microsatellite marker genes such as MEN-1, p53, DCC, and hMSH-2, suggesting significant differences in the pathogenesis and development of the epithelial tumor elements that make up mixed neoplasms ${ }^{[18]}$.

Most of the reports dealing with mixed tumors of the gastrointestinal tract describe low-grade neuroendocrine or carcinoid tumors in conjunction with adenoma. For example, in 1989, Ito et al. reported the case of a 54-year-old with three gastric polyps, one of which contained mixed adenomatous and carcinoid elements with infiltration by both elements into the muscularis mucosa ${ }^{[19]}$. In addition, Pulitzer et al. published a series of four cases of microcarcinoid tumor within colonic adenomatous polyps ${ }^{[3]}$. Most recently, Lin et al. described seven cases of composite adenoma-microcarcinoid tumors involving the small intestine and colon ${ }^{[20]}$. Interestingly, one of the cases was characterized by invasion by carcinoid cells into the submucosa, with subsequent discovery of metastatic high grade neuroendocrine carcinoma in one lymph node. The above described neoplasms were otherwise generally low-grade, limited to the mucosa, and without long term complications.

The present case is unique in that it is one of only very few reported cases of colonic mixed adenoma high-grade neuroendocrine carcinoma, as confirmed by the morphology and increased proliferation index of $90 \%$. As mentioned above, high-grade neuroendocrine carcinomas of the colon are generally rare, but interestingly when they do occur, there is evidence to support a strong association with tubulovillous/villous adenomas. This was demonstrated by Mills et al. who in 1983 found that of five cases of small cell carcinoma of the colon, four had adjacent tubulovillous/villous adenomas, while the fifth had a history of colonic adenomas ${ }^{[21]}$. Based on the few reported cases, these lesions tend to behave very aggressively. Metastatic disease often presents at the time of diagnosis with the liver and skeletal system most commonly involved. The prognosis is extremely poor with survival lasting a few months, which is drastically worse than standard colonic adenocarcinoma ${ }^{[16]}$.

A number of practical points may be garnered from this case. First, superficial biopsy specimens often do not provide adequate representation of underlying neuroendocrine neoplasms found in mixed tumors. In one of three cases reported by Silverman et al., an underlying neuroendocrine malignancy was missed due to the superficial nature of the biopsy ${ }^{[22]}$. Second, even when present in the biopsy material, the pathologist must be cognizant of the possibility of a mixed neoplasm and resist the tendency to diagnose an adenoma before careful inspection of the tissue for a second lesion. Third, it is important to consider the colon as a possible origin, in cases of metastatic high-grade neuroendocrine carcinoma of unknown primary. Again, this primary high-grade tumor may be masked by overlying adenoma making it imperative to collect adequate and deep tissue samples. The current case demonstrates some of these possible pitfalls. Metastatic high-grade neuroendocrine carcinoma was identified, and initial biopsy of the patient's colonic mass revealed only tubulovillous adenoma, suggesting that the two lesions were unrelated. It was only after complete resection and thorough review by the pathologist that a deeper and invasive high-grade neuroendocrine carcinoma was present.

The pathologist must also be aware of the differential diagnosis of poorly differentiated neoplasms that may involve an adenoma. This includes poorly differentiated adenocarcinoma and lymphoma. Being that the prognosis and management varies significantly amongst these entities, careful attention must be paid to the morphology of the tumor cells and general architecture. In addition, a panel of immunohistochemical stains that includes neuroendocrine, lymphocytic, and adenocarcinoma markers should be employed to ensure correct diagnosis.

\section{Competing interests}

The authors declare that they have no competing interests. 


\section{References}

[1] Capella, C, La Rosa S, Uccella S, Billo P, Cornaggia M. Mixed endocrine-exocrine tumors of the gastrointestinal tract. Semin Diagn Pathol. 2000; 17(2): 91-103. PMid: 10839609.

[2] Lewin K. Carcinoid tumors and the mixed (composite) glandular-endocrine cell carcinomas. Am J Surg Pathol. 1987 ; 11 Suppl 1: 71-86. PMid: 3544888. http://dx.doi.org/10.1097/00000478-198700111-00007

[3] Pulitzer M, Xu R, Suriawinata AA, Waye JD, Harpaz N. Microcarcinoids in large intestinal adenomas. Am J Surg Pathol. 2006; 30(12): 1531-6. PMid: 17122508. http://dx.doi.org/10.1097/01.pas.0000213295.88778.00

[4] Erbil Y, Barbaros U, Kapran Y, Yanik BT, Bozbora A, Ozarmagan S. Synchronous carcinoid tumour of the small intestine and appendix in the same patient. West Indian Med J. 2007; 56(2): 187-9. PMid: 17910153. http://dx.doi.org/10.1590/S0043-31442007000200016

[5] Modlin IM, Kidd M, Latich I, Zikusoka MN, Shapiro MD. Current status of gastrointestinal carcinoids. Gastroenterology. 2005; 128(6): 1717-51. PMid: 15887161. http://dx.doi.org/10.1053/j.gastro.2005.03.038

[6] Modlin IM, Shapiro MD, Kidd M, An analysis of rare carcinoid tumors: clarifying these clinical conundrums. World J Surg. 2005; 29(1): 92-101. PMid: 15599742. http://dx.doi.org/10.1007/s00268-004-7443-z

[7] Brenner B, Shah MA, Gonen M, Klimstra DS, Shia J, Kelsen DP. Small-cell carcinoma of the gastrointestinal tract: a retrospective study of 64 cases. Br J Cancer. 2004; 90(9): 1720-6. PMid: 15150595.

[8] Brenner B, Tang LH, Klimstra DS, Kelsen DP. Small-cell carcinomas of the gastrointestinal tract: a review. J Clin Oncol. 2004. 22(13): 2730-9. PMid: 15226341. http://dx.doi.org/10.1200/JCO.2004.09.075

[9] Nassar H, Albores-Saavedra J, Klimstra DS. High-grade neuroendocrine carcinoma of the ampulla of vater: a clinicopathologic and immunohistochemical analysis of 14 cases. Am J Surg Pathol. 2005; 29(5): 588-94. PMid: 15832081. http://dx.doi.org/10.1097/01.pas.0000157974.05397.4f

[10] Shia J, Tang LH, Weiser MR, Brenner B, Adsay NV, et al. Is nonsmall cell type high-grade neuroendocrine carcinoma of the tubular gastrointestinal tract a distinct disease entity? Am J Surg Pathol. 2008; 32(5): 719-31. PMid: 18360283. http://dx.doi.org/10.1097/PAS.0b013e318159371c

[11] Tasso DM, Attam R, Aslan DL, Pambuccian SE. Endoscopic ultrasound guided fine-needle aspiration diagnosis of duodenal high grade neuroendocrine carcinoma underlying a villous adenoma: report of a case. Diagn Cytopathol. 2012; 40(1): 62-8. PMid: 22180240. http://dx.doi.org/10.1002/dc.21603

[12] Klimstra DS, Modlin IR, Coppola D, Lloyd RV, Suster S. The pathologic classification of neuroendocrine tumors: a review of nomenclature, grading, and staging Systems. Pancreas. 2010; 39(6): 707-712. PMid: 20664470. http://dx.doi.org/10.1097/MPA.0b013e3181ec124e

[13] Rindi G, Arnold R, Bosman FT, Capella C, Klimstra DS, et al. Nomenclature and classification of neuroendocrine neoplasms of the digestive system. In: Bosman FT CF, Hruban RH, Theise N., editor. WHO classification of tumors of the digestive system. 4th ed. Lyon: International Agency for Research on Cancer. 2010; 13-14.

[14] Bosman F, Carneiro F, Hruban R, Theise N, eds. WHO Classification of Tumours of the Digestive System. Lyon, France: IARC Press. 2010.

[15] Barnhill M, Hess E, Guccion JG, Nam LH, Bass BL, Patterson RH. Tripartite differentiation in a carcinoma of the duodenum. Cancer. 1994; 73(2): 266-72. http://dx.doi.org/10.1002/1097-0142(19940115)73:2<266::AID-CNCR2820730206>3.0.CO;2-\#

[16] Ispas C, Yu J, Tarantino DR, Lara JF. Pathologic quiz case: a 44-year-old woman with a tubulovillous adenoma of the colon and liver and bone lesions. Small cell (neuroendocrine) carcinoma of the colon with metastasis and an associated, overlying villous adenoma. Arch Pathol Lab Med. 2005; 129(3): 412-4. PMid: 15737043.

[17] Sun JH, Chao M, Zhang SZ, Zhang GQ, Li B, Wu JJ. Coexistence of small cell neuroendocrine carcinoma and villous adenoma in the ampulla of Vater. World J Gastroenterol. 2008; 14(29): 4709-12. PMid: 18698690. http://dx.doi.org/10.3748/wjg.14.4709

[18] Ubiali A, Benetti A, Papotti M, Villanacci V, Rindi G. Genetic alterations in poorly differentiated endocrine colon carcinomas developing in tubulo-villous adenomas: a report of two cases. Virchows Arch. 2001; 439(6): 776-81. PMid: 11787850. http://dx.doi.org/10.1007/s004280100475

[19] Ito H, Ito M, Tahara E. Minute carcinoid arising in gastric tubular adenoma. Histopathology. 1989; 15(1): 96-9. PMid: 2767625. http://dx.doi.org/10.1111/j.1365-2559.1989.tb03046.x

[20] Lin J, Goldblum JR, Bennett AE, Bronner MP, Liu X. Composite intestinal adenoma-microcarcinoid. Am J Surg Pathol. 2012; 36(2): 292-5. PMid: 22082602. http://dx.doi.org/10.1097/PAS.0b013e318236e4d2

[21] Mills SE, Allen MS Jr, Cohen AR. Small-cell undifferentiated carcinoma of the colon: a clinicopathologic study of 5 cases and their association with colonic adenomas. Am J Surg Pathol. 1983; 7(7): 643-651. PMid: 6314828. http://dx.doi.org/10.1097/00000478-198310000-00005

[22] Silverman JF, Baird DB, Teot LA, Cappellari JO, Geisinger KR. Fine-needle aspiration cytology of metastatic small cell carcinoma of the colon: a report of three cases. Diagn Cytopathol. 1996; 15(1): 54-9.

http://dx.doi.org/10.1002/(SICI)1097-0339(199607)15:1<54::AID-DC11>3.0.CO;2-B 